\title{
Generation and trapping of $\alpha$-oxa and oxo o-quinodimethanes for natural product synthesis
}

\author{
Satincier V. Kessar \\ Chemistry Department, Panjab University, Chandigarh-14, India
}

Abstract - Photolysis of 1-o-toluyl-3,4-dihydroisoquinolines gives protoberberine alkaloids through the intermediacy of $\alpha$-hydroxy quinodimethanes and spirobenzylisoquinol ines. Ortho trimethylsilylmethyl benzoyl chlorides on treatment with fluoride ions afford ketene quinodimethanes which can be trapped with reactive dienophiles. The reactivity pattern of these intermediates is considered in terms of the frontier molecular orbital theory. The synthetic utility of some ketene-quinodimethane equivalents is discussed.

Ortho-quinodimethanes have attracted considerable attention ever since the pioneering work of Cave (ref. 1). Their immense synthetic potential was demonstrated by Oppolzer, Kametani, Vollhardt, Magnus, Ito and others (ref. 2). For some time we have been interested in $\alpha$-oxa and $\alpha$-oxo $o$-quinodimethanes which on trapping can produce target molecules with additional inbuilt structural features, especially the anthracyclines, the lignans and the alkaloids.

Some novel aspects of purely chemical interest are also associated with these reactive intermediates $e . g$. , the unique molecular orbital array of ketenequinodimethane can have an intriguing bearing on the reactivity and the regioselectivity in their $4 \pi+2 \pi$ cycloadditions. The $\alpha$-hydroxy quinodimethanes which are readily generated through photoenolisation (ref. 3 ) can undergo, besides the widely explored cycloaddition, interesting reactions with electrophiles. He have investigated the competition between these two processes in the substrates of the type shown in fig. 2. Here the hydroxyquinodimethane, formed on irradiation, can yield a protoberberine (path $A$ ) or a spirobenzylisoquinoline (path B) alkaloid.

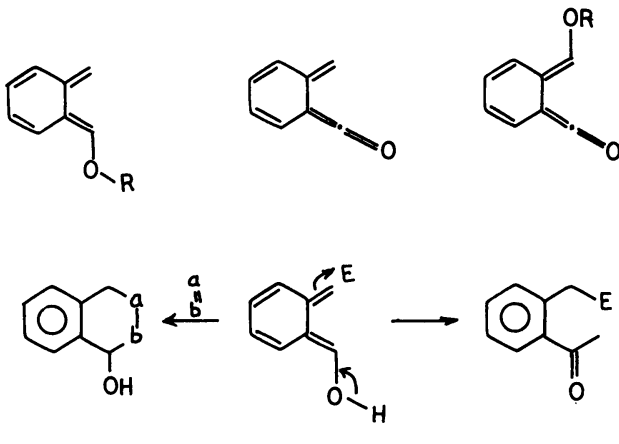

Fig. 1
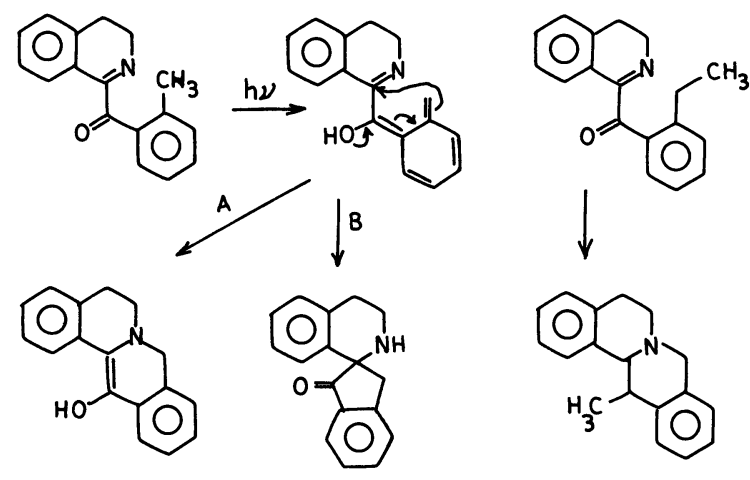

Fig. 2

In the event, photolysis of the $\alpha$-keto-imines in methanol followed by sodiumborohydride treatment, smoothly gave protoberberines. A few alkaloids were synthesised in this manner in yields ranging from 20 to $50 \%$ (ref. 4). The procedure is also applicable for the synthesis of the corresponding indole alkaloids (ref. 5). Thus it seemed that electrocyclic ring closure pathway (A) prevails. However, unexpected results were obtained when synthesis of the alkaloids with an unsymmetrical substitution pattern in ring C or D was undertaken. For example, the ethyl keto-imine on irradiation gave a 13-methylprotoberberine instead of the anticipated 8-methyl protoberberine. Similarly, 11,12-alkaxy compounds were obtained while the 9,10-alkoxy alkaloids were expected. The observed transposition of the groups may be explained in terms of the initial formation of a spiroketone (path B) and its rapid subsequent transformation (ref.6) as shown (Fig. 3). 


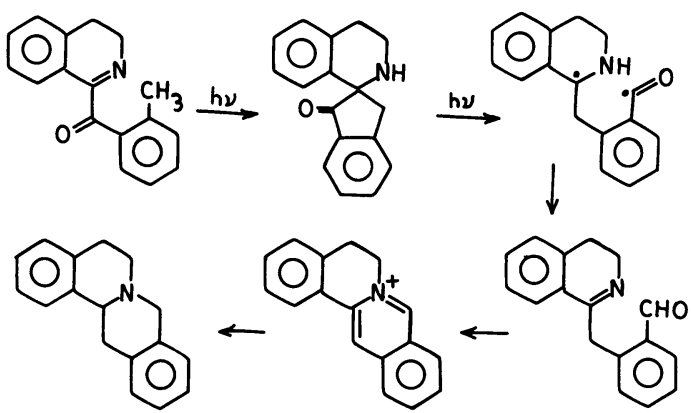

Fig. 3
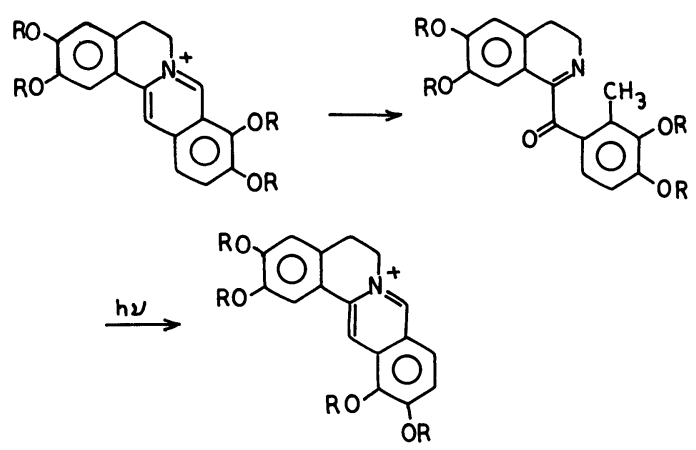

Fig. 4

For the formation of the spiroketone itself a number of pathways can be visualised but it is difficult to experimentally distinguish between the alternatives. However, the mechanism for further conversion to protoberberines has been investigated. In the diradical formed on $\alpha$-cleavage, a 1,6- or a 1,4-hydrogen shift can take place and there is no priori reason to favour one over the other. When the photolysis was carried out in $\mathrm{CH}_{3} \mathrm{OD}$, good deuterium incorporation at position 8 occurred indicating a 1,6-hydrogen shift.

The above photoreaction of keto-imines, in conjunction with a known degradation of protoberberine alkaloids affords an amusing swapping of the ring D substituents (ref. 7 ). Whereas our reaction involves conversion of the intermediate spiro alkaloids to protoberberines, a reverse transformation is also possible. Manske (ref. 8) has rationalised it in terms of electrocyclic ring opening followed by quinodimethane reaction by path $B$. However, an excited state allowed 1,2-migration also merits consideration (Fig. 4).

Interpretation of cycloaddition reactions of ketenes in terms of the frontier molecular orbitals has evoked considerable attention. Vinyl ketene presents an even more interesting scenario, especially with respect to its $4 \pi+2 \pi$ additions. However, experimentally these are difficult to investigate because of the propensity for $2+2$ additions (ref. 9 ), but ketenequinodimethanes (KQDM) are amenable to such a study. For this purpose, and for possible synthetic applications it was considered desirable to generate KQDM intermediates in their ground state and at low temperatures. The procedure adopted by us is shown (ref. 10). Although

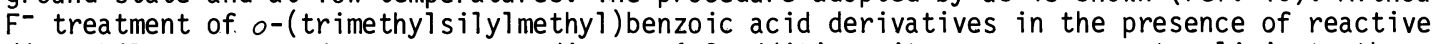
dienophiles gave products corresponding to $4+2$ addition, it was necessary to el iminate the alternate Michael addition ring closure pathway. In fact, contemporaneous work of Achiwa (ref. 11) indicates that in silyl esters, with a weaker alkoxy leaving group, such a process does incur. Also in our own studies on a silyl acetal, a Michael adduct was isolated and a-alkoxy quinodimethane derived products could not be detected (ref. 12). It is, therefore, necessary to establish the KQDM intermediacy (Fig. 5).

When the $\mathrm{F}^{-}$ion treatment of the silyl acid chloride was carried out in the absence of a reactive dienophile, two dimeric products were isolated. While the formation of the isocoumarin can be explained through either pathway, the olefinic material can arise only from a quinodimethane. Formation of both the dimers is supressed in the presence of the reactive dienophiles, which supports but does not conclusively prove KQDM intermediacy (Fig. 6).

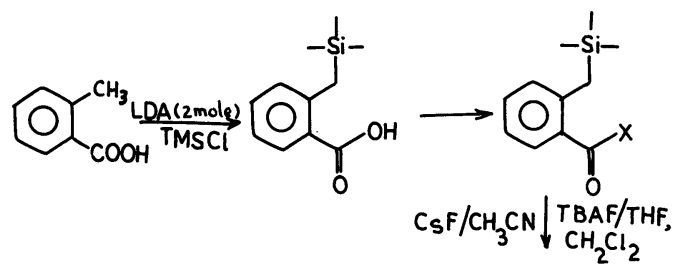

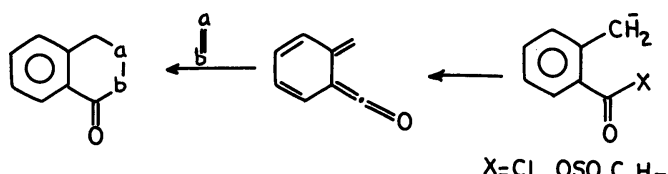<smiles>Cc1ccccc1C(=O)Cl</smiles><smiles>CC(C)CCCCC(=O)Cl</smiles>

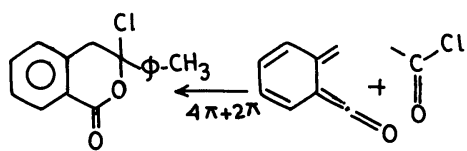<smiles>[X]C(=O)c1ccccc1C</smiles><smiles>[H][Y9]1OCc2ccccc2C1=O</smiles><smiles>Cc1ccc2c(c1)C(=O)PCO2</smiles>

Fig. 5<smiles>C[Si](C)(C)Cc1ccccc1C(=O)Cl</smiles><smiles>Cc1ccccc1-c1cc2cc(C(F)(F)F)ccc2c(=O)o1</smiles>
$\downarrow 2 \pi+2 \pi$

Fig. 6 


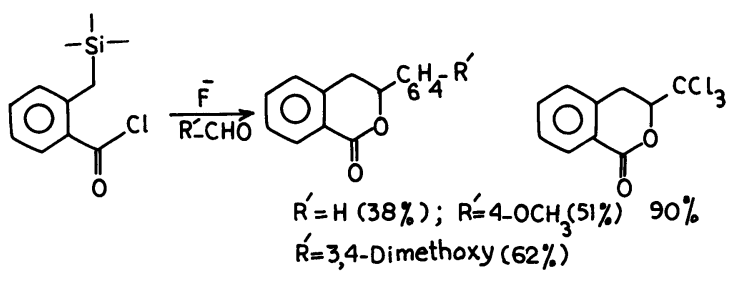<smiles>O=C1OC(c2ccc(O)cc2)Cc2cccc(O)c21</smiles>

HYDRAGENOL<smiles>COc1ccc(C2Cc3cccc(O)c3C(=O)O2)cc1O</smiles>

PHYLLODULCIN

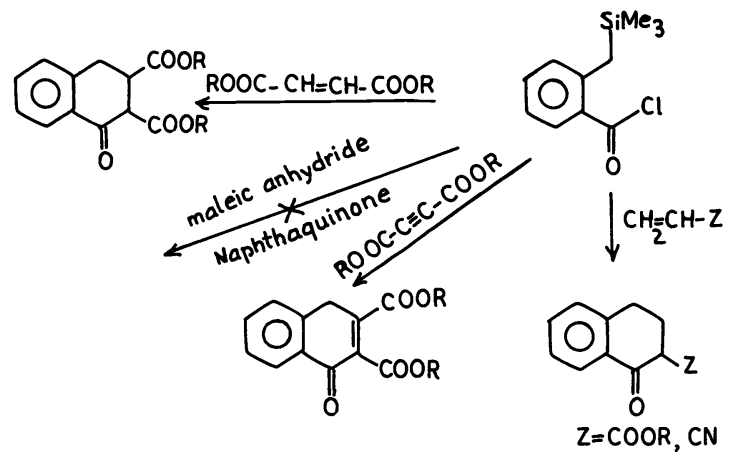

Fig. 7

The reaction of the silyl acid chloride with aromatic aldehydes proceeded efficiently. The procedure can be used for the synthesis of naturally occurring dihydroisocoumarins some of which show pronounced sweatening properties and antifungal activity (ref. 13) (Fig. 7).

0lefinic dienophiles are less efficient trapping agents and with weak dienophiles no adducts could be obtained. It may be noted that maleic anhydride and naphthaquinone also failed to yield adducts. It seems with these dienophiles, $F^{-}$plays some role as normal addition is observed when the KQDM is generated otherwise (ref. 14) (Fig. 8).

Lowering of the KQDM reactivity by the carbonyl group is also evident from the attempted intramolecular trapping which failed in contrast to the results with the unsubstituted quinodimethanes (ref. 15) (Fig. 9).

The behaviour of KQDM may be analysed in terms of the carbonyl perturbation of the conjugated diene. In the orientation of the $4 \pi+2 \pi$ addition, $i . e$. the formation of the ortho products, it acts like an electron supplying ( $Z$ ) substituent. However, such groups are known to enhance the diene reactivity whereas it is being depressed here. Thus this perturbation is unique, like that of an electron supplying group for orientation and like that of an electron withdrawing group for reactivity. An explanation may be sought in terms of the coefficients and the energies of the KQDM frontier orbitals calculated (CNDO/2) by Kuzuya (ref. 16). On the basis of the lesser energy difference, the diene HOMO and the dienophile LUMO are the relevant orbitals as in the usual $4 \pi+2 \pi$ additions (Fig. 10).

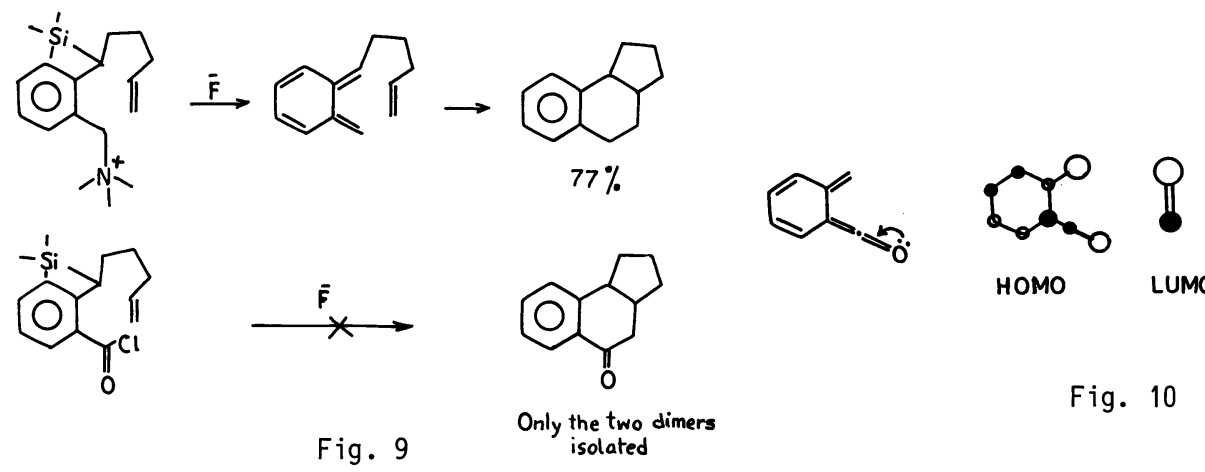

It can be seen that in the HOMO of KQDM, the carbon atom farthest from the carbonyl has the largest coefficient, 1 ike in 1-methoxybutadiene. Hence similar regio selectivity may be expected. On the other hand, the energy of this HOMO is lowered instead of being raised. The consequent increase in the energy gap with the dienophile LUMO can explain the lowering of the reactivity.

It was of interest to see if the KQDM reactivity can be boosted by appending suitable electron supplying groups. The trimethylsilyl KQDM derived from the disilyl acid chloride showed no marked improvement. In this context we have also looked at $\alpha$-hydroxy KQDM which can be easily obtained, from the shown aldehyde esters by irradiation, and trapped by maleic anhydride (ref. 17). Although aryl amides do not readily abstract a hydrogen from an ortho alkyl group, it was thought that the transfer of the ortho aldehydic hydrogen may occur in the excited state. On this basis a synthesis of 12-hydroxy-benzo|c|phenanthridines was devised. Irradiation of the shown aldehydic amide did not yield the desired cyclic adduct. However, an amino lactone was obtained which showed that KQDM is formed but it does not get trapped by the styryl double bond (Fig. 11). 
<smiles>[R]C(=O)c1ccccc1C(=O)O</smiles>

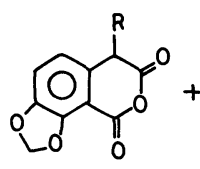<smiles>CN=Cc1cc2c(cc1C[Si](C)(C)C)OCCO2</smiles>

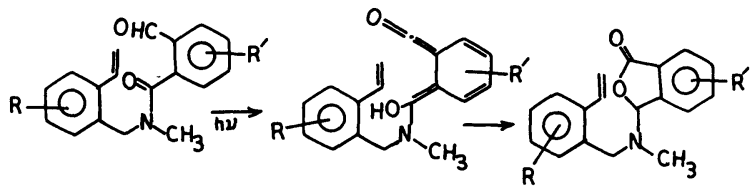

Fig. 12

no $4 \pi+2 \pi$ adducts

Fig. 11

In the end we may consider some masked KQDM equivalents which can serve the synthetic purpose, though the overall sequence may involve additional steps. Ito has reported the generation and the trapping of $\alpha$-imino and $\alpha$-dithio o-quinodimethanes (ref. 18, 19). In contrast to the oxo-analogues, with imines a $2 \pi+2 \pi$ electrocyclic ring closure was observed in the absence of dienophiles. Exclusive formation of a $4 \pi+4 \pi$ cyclo adduct occurred with the thio compound. It would be interesting to examine these differences in the light of the FMO energies and the steric effects.

Tamura has shown (ref. 20) that homophthalic anhydride on heating $\left(200^{\circ} \mathrm{C}\right.$ ) with dienophiles furnishes adducts. These workers consider the reaction as a cyclo addition of an enolic form, followed by decarboxylation. In fact the reaction can be performed at low temperatures with the corresponding anions and is viewed as an activated $4 \pi+2 \pi$ cyclo addition (ref. 21 ). Earlier Cushman had uncovered a very useful reaction of homophthal ic anhydride with Sch iff bases which was used in a number of elegant alkaloid syntheses (ref. 22). We have developed a route to 11-hydroxy benzo|c|phenanthridine alkaloids along similar lines. The key step involves a $\mathrm{F}^{-}$ion initiated desilylation to build the D ring (Fig. 12).

I would like to conclude by expressing my gratitude to my coworkers, especially Drs. Y.P. Gupta, Paramjit Singh, T.V. Singh, A.K. Nanda, K.R. Agnihotri, Miss Seema Gupta and

D. Venugopal.

\section{REFERENCES}

1. M.P. Cava, D.R. Napier, J. Am. Chem. Soc. 79, 1701 (1957).

2. W. Oppolzer, Synthesis, 793 (1978).

3. P.G. Sammes, Tetrahedron 32, 405 (1976).

4. S.V. Kesser, Y.P. Gupta, Paramjit Singh and A.K. Nanda, J. Chem. Soc. Chem. Commun., 885 (1978).

5. Y. Hirai, H. Egawa and T. Yamazaki, Heterocycles 22, 1359 (1984).

6. H. Irie, K. Akagi, S. Tani, K. Yabusaki and H. Yamana, Chem. Pharm. Bull. 21, 855 (1973); D. Greenslade and R. Ramage, Tetrahedron 33, 927 (1977); cf. N.K. Hammer, J. Chem. Soc. Perkin I, 508 (1979).

7. S.V. Kessar, Y.P. Gupta, T.V. Singh, A. Sood, A.K. Nanda and K.R. Agnihotri, Tetrahedron Lett. 23, 3619 (1982); Tai-Teh Wu, J.L. Moniot and I. Shamma, Tetrahedron Lett. 37, 3419 $(1978)$

8. B. Nalliah, R.H.F. Manske, R. Rodrigo, D.B. MacLean, Tetrahedron Lett. 29, 2795 (1973).

9. This situation may be altered by appending a trimethy|silyl group, R.L. Danheiser and H. Sard, J. Org. Chem. 45, 4810 (1980).

10. S.V. Kessar, P. Singh and D. Venugopal, J. Chem. Soc. Chem. Commun., 1258 (1985).

11. M. Aono, Y. Terao and K. Achiwa, Chemistry Letters, 339 (1985).

12. cf. R.J. Moss and B. Rickborn, J. Org. Chem. 49, 3694 (1984).

13. M. Wa tanabe, M. Sahara, M. Kubo, S. Furukawa, R.J. Billedeau and V. Snieckus, J. Org. Chem. 49, 742 (1984).

14. P. Schiess, M. Eberle, M.H. Francotte and J. Wirz, Tetrahedron Lett. 25, 2201 (1984).

15. Y. Ito, M. Nakatsuka and T. Saegusa, J. Am. Chem. Soc. 104, 7609 (1982).

16. K. Kuzuya, F. Miyake and T. Okuda, Te trahedron Lett. 21,2185 (1980).

17. R.J. Spangler, L.G. Henscheid and K.T. Buch, J. Org. Chem. 42, 1693 (1977).

18. Y. I to, E. Nakajo and T. Saegusa, Tetrahedron Lett. 25,5139 (1984).

19. Y. I to, E. Nakajo, K. Sho and T. Saegusa, Synthesis, 698 (1985).

20. Y. Tamura, A. Hada, M. Sasho and Y. Kita, Tetrahedron Lett. 22, 4283 (1981).

21. Y. Tamura, M. Sasho, K. Nakagawa, T. Trugoshi and Y. Kita, J. Org. Chem. 49, 476 (1934);

Y. Tamura, F. Fakata, H. Sasho, T. Trugoshi and Y. Kita, J. Org. Chem. 50, 2273 (1985).

22. M. Cushman, J. Gentry and F.W. Dekow, J. Org. Chem. 42, 1111 (1977); M. Cushman,

A. Abbaspour and Y.P. Gupta, J. Am. Chem. Soc. 105, 2371 (1983). 